\title{
MECHANISMS IN ENDOCRINOLOGY \\ MicroRNA in diagnostics and therapy of thyroid cancer
}

\author{
Anna Wójcicka ${ }^{1,2}$, Monika Kolanowska ${ }^{1,2}$ and Krystian Jażdżewski ${ }^{1,2}$ \\ ${ }^{1}$ Genomic Medicine, Medical University of Warsaw, Żwirki i Wigury 61, 02-097 Warsaw, Poland and ${ }^{2}$ Human Cancer \\ Genetics, Centre of New Technologies, CENT, University of Warsaw, Banacha 2c, 02-097 Poland
}

Correspondence should be addressed to K Jażdżewski Email krystian.jazdzewski@ wum.edu.pl

\begin{abstract}
\end{abstract}
MicroRNAs, short non-coding regulators of the gene expression, are subjects of numerous investigations assessing their potential use in the diagnostics and management of human diseases. In this review, we focus on studies that analyze the utility of microRNAs as novel diagnostic and therapeutic tools in follicular cell-derived thyroid carcinomas. This very interesting and promising field brings new insight into future strategies for personalized medicine.

European Journal of Endocrinology (2016) 174, R89-R98

\section{MicroRNA function and biogenesis}

MiRNAs act via annealing to transcripts of protein-coding genes and inhibiting further steps of their expression. This interaction depends on the Watson-Crick complementarity between the seed region, located between the second and the eighth miRNA nucleotides, and the target sequence located in mRNA (5). Although most miRs recognize sequences within the $3^{\prime}$ untranslated regions ( $3^{\prime}$ UTRs) of target mRNAs, still a large number of interactions occurs within the coding sequence of the target gene (6). It is estimated that microRNAs regulate the expression of at least a half of the human protein-coding transcripts (7).

Tissue specificity of microRNA expression adds to the stringency of mechanisms, which maintains the

\section{Invited Author's profile}

Krystian Jazdzewski, MD, PhD, is the head of an interdisciplinary group comprising medical doctors, molecular biologists, and geneticists from Genomic Medicine (Medical University of Warsaw) and the Laboratory of Human Cancer Genetics (Centre of New Technologies, University of Warsaw) in Poland. The group analyzes the function of regulatory RNAs and the role of their disturbed expression in the development and progression of cancer. They aim to elucidate noninvasive molecular panels based on microRNA expression that will allow for diagnostics and prognostics of human cancers. Prof. Jazdzewski has published several papers in all leading peer-reviewed journals.

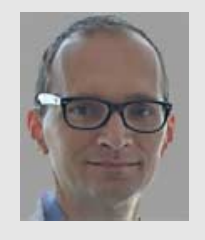

(c) 2016 European Society of Endocrinology Printed in Great Britain
Published by Bioscientifica Ltd. 
development and differentiation of cells. MiRNAs play an important role in apoptosis (8) and proliferation (9). Importantly, because a single miR regulates several target mRNAs, and a single mRNA is regulated by $\sim 100$ miRNAs (10), the combined effects of deregulation of miRNA expression can induce strong biological responses. MiRs are involved in the regulation of many different types of genes, including oncogenes and tumor suppressors, and more than one-half of annotated miRNAs are located in fragile sites associated with cancer $(11,12)$.

MicroRNAs are encoded all over the genome, mainly in introns of protein-coding genes. MiRs are first expressed as long primary transcripts (pri-miRNAs) that are cleaved to produce $\sim 60 \mathrm{nt}$ long microRNA precursors (premiRNAs) (13). Pre-miRNAs fold into specific secondary structures of hairpins and are further cleaved by the Dicer RNase to produce mature miRNA molecules from each strand of the hairpin (5) (Fig. 1).

Recent studies revealed that a single miRNA gene might give rise to isomiRs, numerous mature miRNA molecules of different length (14). This fact is of profound importance for miRNA's function, because the addition or deletion of nucleotides at the isomiR $5^{\prime}$ end results in a change in the seed region and, consequently, leads to the regulation of a distinct set of target genes compared to

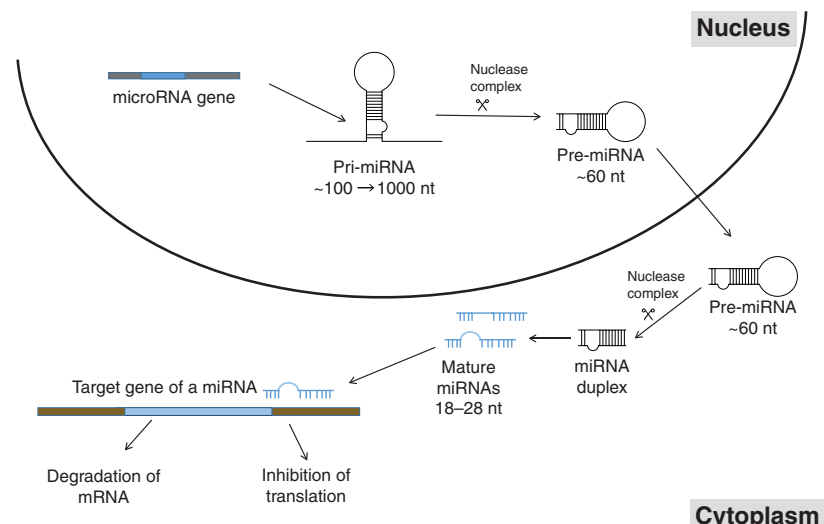

\section{Figure 1}

MicroRNA biogenesis. MicroRNA gene is expressed in a form of a long (hundreds to thousands of nucleotides) primary transcript (pri-miRNA), which is cleaved to produce $\sim 60 \mathrm{nt}$ long pre-miRNA. In cytoplasm, pre-miRNA is further cleaved by the RNAse complex to give a miRNA duplex comprising two mature miRNA molecules, each arising from one arm of the hairpin. One of the mature miRs is loaded into RNA-Induced Silencing Complex (RISC), the other miR is degraded. the isomiR's canonical counterpart. As functional partners of their reference canonical molecules, isomiRs are tissue specific; therefore, the proper interpretation of microRNA-regulated networks requires comprehensive information on the miRNome for each particular tissue type $(15,16,17)$.

\section{MicroRNAs of the thyroid gland}

This review focuses on microRNAs implicated in the pathogenesis of the follicular cell-derived thyroid carcinomas. A recent next-generation sequencing study revealed that although 2588 human microRNAs are deposited in miRbase 21 (18), only 427 miRs are expressed at a significant level ( $>5$ reads per million reads (RPMs)) in the thyroid gland (19). The study also showed that the 427 thyroid miRs exist in 1749 length isoforms, and novel isomiRs are often expressed at higher levels compared to their canonical counterparts. If the length variation affects the miRNA $5^{\prime}$ end, a novel seed is created leading to an altered regulatory function. This fact is of great importance for the proper understanding of the miR-mediated processes in the thyroid cells; however, traditionally used microarray and TaqMan analyses could not distinguish between most of the length variants. In papillary thyroid carcinoma (PTC), 427 expressed miRs created almost 100 novel regulatory seeds, while the total number reached 513. Even though the expression of a single microRNA can be relatively low, the action of all isoforms carrying the same seed region (so-called seed power) can induce strong biological responses (19).

The role of microRNAs in thyroid tumors has been studied for a long time, revealing specific expression patterns of miRs. Most profiling studies in thyroid cancers were performed using oligo DNA microarrays (see Table 1). The studies showed that different cancer types exhibit deregulation of different microRNAs, proving the existence of cancer-specific signatures of microRNA expression $(20,21,22,23,24)$. These observations were recently confirmed in the next-generation sequencing of thyroid tumors $(19,25)$. The studies showed that PTC is accompanied by a significant upregulation of the miR$146,-181,-221 / 222$, and -224 families; follicular thyroid carcinoma (FTC) exhibits upregulation of the miR-181 and -200 families and downregulation of the miR-199 family, and anaplastic thyroid carcinoma (ATC) is characterized by elevated levels of miR-17 and -221/222 and downregulation of the let-7 and miR-30 and -29 families. A list of the top deregulated miRs identified in different studies is presented in Table 1. 


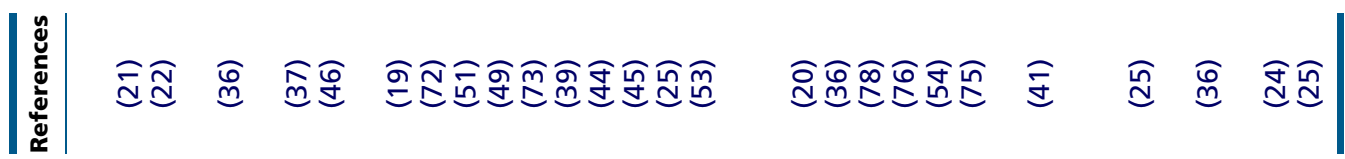
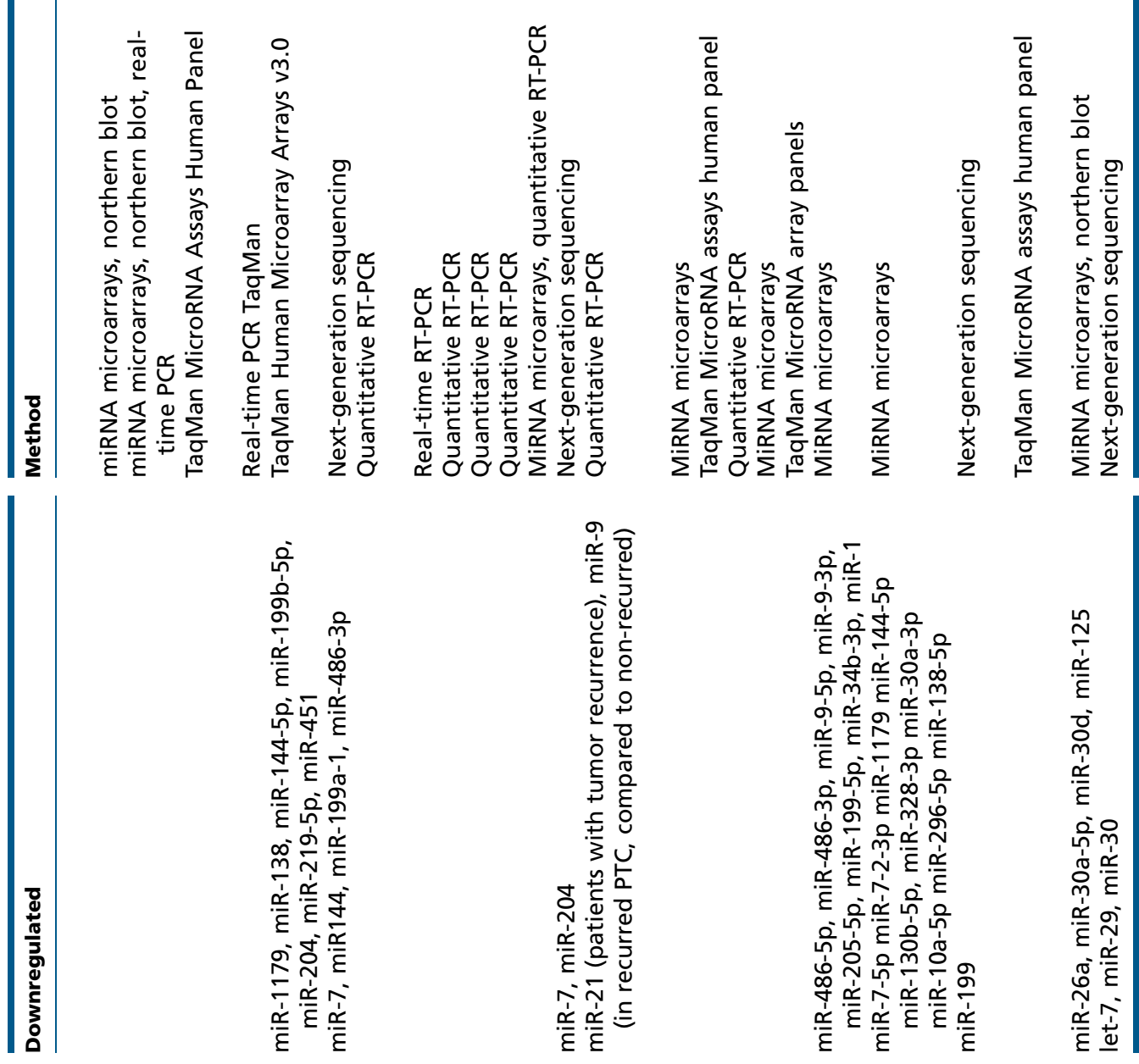
Such tumor specificity of microRNA expressions suggests their possible use as cancer biomarkers. Indeed, numerous studies aimed at the elaboration of microRNAbased prognostic and diagnostic tools for thyroid cancers. The results of this quest are described in more detail below.

\section{MicroRNA-mediated thyroid cancer risk}

The familial risk for PTC is associated with a single nucleotide polymorphism (SNP) within the miR-146a-3p (rs2910164 G > C), which alters both expression levels and gene targeting by the miR $(26,27)$. A case-control study performed in 608 patients from Polish, American, and Finnish populations revealed that the G/C heterozygosity is a risk factor predisposing to $\mathrm{PTC}(\mathrm{OR}=1.62 ; 95 \% \mathrm{CI} 1.3-$ 2.0; $P=0.000007)$, with the CC state being protective $(\mathrm{OR}=0.42 ; 95 \% \mathrm{CI} 0.24-0.73, P=0.0027)$. The same study revealed that tumor DNA of up to $6 \%$ of patients undergoes somatic mutations within rs2910164, which additionally confirmed the role of this variant in the pathogenesis of PTC (26). The rs2910164-mediated predisposition was further analyzed in 781 thyroid cancer patients recruited in the United Kingdom (28), and the study revealed no association between the polymorphism and thyroid cancer risk. Similar results were obtained in 753 Chinese patients (29) and in 307 Italian patients (30). However, meta-analyses revealed a strong association of the SNP with the cancer risk in the Caucasian population (30). Interestingly, another study performed in FTC and follicular adenomas (FA) showed that the CC genotype within the rs2910164 was completely absent in FTC tumors. The authors proposed that the SNP could be correlated with the transition from normal to neoplastic thyroid tissue (23). It is worth mentioning that rs2910164 has been later shown to predispose to hepatocellular carcinoma in males (31), prostate cancer (32), bladder cancer (33), and colorectal cancer (34). Rs2910164 is also proposed to contribute to the pathogenesis of breast and ovarian cancer, as the target genes of miR-146a include BRCA1 and BRCA2. Breast cancer patients who had at least one miR-146a variant allele were diagnosed at an earlier age than the patients with no variant alleles (35).

\section{MicroRNAs in thyroid cancer diagnostics: analysis of microRNAs in fine-needle aspiration (FNA) and tissue specimens}

Thyroid nodules are the most common thyroid disease and an estimated $50 \%$ of the general population has nodules detectable by ultrasonography. However, only $5 \%$ of all thyroid nodules harbor malignancy; therefore, preoperative differentiation of benign and malignant lesions is crucial, although not always possible with the use of traditional FNA biopsy and cytological examination. Several studies attempted to elaborate specific microRNA diagnostic panels that would enable higher specificity and sensitivity in differentiation between benign and malignant thyroid nodules.

Nikiforova et al. performed microRNA profiling of various thyroid tumors and proposed a set of miR-146b, $-155,-187,-197,-221,-222$, and -224 as potentially distinguishing between the analyzed sample types. The chosen miRs were quantified in 62 FNA samples and the authors claimed that, when at least one miRNA was overexpressed over twofold, the sensitivity of cancer detection was $100 \%$, specificity $94 \%$, and accuracy $95 \%$. When three or more miRNAs were upregulated, the sensitivity of cancer detection was $88 \%$, with a specificity of $100 \%$ and accuracy of $98 \%$ (36). The clinical utility of the same microRNA panel was further evaluated in a set of 141 FNA specimens, revealing that the decision model based on the expression of miR-146b, -155, and -221 had a validity of $97.7 \%$ (59\% in nodules with undetermined cytology) and reliability of $78.4 \%$ (37). In a study by Kitano et al., the authors chose a diagnostic set of four different microRNAs: miR-7, -126 , and -374a and let-7g. The analysis performed in 154 FNA specimens revealed that among the chosen miRs only miR-7 actually distinguished between malignant and benign tissue. The proposed predictor model had an overall accuracy of $37 \%$ with the sensitivity of $100 \%$ and specificity of $20 \%$, while positive predictive values and negative predictive values reached 25 and 100\% respectively (38). Another study analyzed the expression of miR-146b-5p and miR-21 in various thyroid nodules using in situ hybridization in formalin-fixed paraffin-embedded specimens (39). The study showed high overexpression of miR-146b-5p in PTC (89\%) and follicular variant of PTC (fvPTC, 41\%), whereas the miR was not detected in most FTCs, ATCs, poorly differentiated thyroid carcinomas (PDTCs), or FAs. MiR-21 was overexpressed in $83 \%$ of ATCs, $79 \%$ of PTCs, $34 \%$ of fvPTCs, and $19 \%$ of PDTCs, but not in FAs or FTCs. The utility of quantification of the miR-221/222 cluster together with analysis of BRAF V600E mutation and galectin-3 protein expression was assessed in 120 FNA samples with indeterminate cytology. Compared with a postoperative histopathological diagnosis, the proposed markers showed the sensitivity of $73.5 \%$, specificity of $89.8 \%$, and accuracy of $75.7 \%$ (40). 
Cytological diagnostics of follicular lesions is considered a grey area in thyroid pathology. Distinguishing between FTC and follicular adenoma in FNA material is one of the most challenging tasks, thus another study specifically addressed the search for a malignancy marker in follicular tumors. The identified two-miR-classifier combining miR-486-5p and miR-7-2-3p had the accuracy of $62 \%$, sensitivity of $82.1 \%$, and specificity of $48.8 \%$ (41).

\section{MicroRNAs in thyroid cancer diagnostics: analysis of circulating microRNAs}

Specific microRNAs deregulated in thyroid tumors are secreted to the bloodstream, which makes them promising noninvasive biomarkers for cancer patients. In a large-scale analysis of serum microRNA profiles in 245 subjects, Yu et al. revealed that the levels of let-7e and miR-151-5p and miR-222 were significantly elevated in PTC patients in comparison either to patients with benign nodules or to healthy subjects (42). Depending on the cutoff values, the test achieved $87.8 \%$ sensitivity and $88.4 \%$ specificity. Another recent study revealed that levels of miR-181a-5p were significantly elevated in the plasma of thyroid cancer patients compared with both control subjects and with patients with other types of cancer, including breast, lung and colon cancer or melanoma (43). In yet another study, the authors analyzed the possible use of circulating miR$146 \mathrm{~b}$ and miR-155, -221, and -222. The mean levels of miR$146 \mathrm{~b}$ and miR-155 were higher in the PTC group than in the benign group. MiR-146b distinguished between the groups with $61.4 \%$ sensitivity and $57.9 \%$ specificity, while miR-155 with $74.3 \%$ sensitivity and $63.2 \%$ specificity. The levels of miR-146b, -155, and -222 increased proportionally to tumor size (44). Alternatively, plasma levels of miR-25$3 \mathrm{p}$ and miR-451a were used to distinguish PTC patients from subjects with benign nodules with the sensitivity of 92.8 and $88.9 \%$ and specificity of 68.8 and $66.7 \%$, respectively (45). It is worth mentioning that some studies found miR-451 downregulated, not upregulated, in thyroid cancer $(46,47)$. Most importantly, miR-451 and miR-16 are known to be related to hemolysis and thus not easy to be used as a circulating marker (48). Another study showed a diagnostic utility of miR-145 in serum and FNA (49), even though the expression of this $\mathrm{miR}$ is lower in cancer tissue.

\section{MicroRNAs in cancer prognostics}

MicroRNA expression might also serve as a prognostic factor for the clinical outcome of thyroid cancer patients. Although PTC is associated with relatively low mortality rates, nodal and distant recurrence is observed in $\sim 20 \%$ of patients, significantly worsening the disease outcome. Elucidation of sensitive biomarkers allowing for identification of such patients would significantly facilitate the treatment and monitoring of their health status. In PTC, miR-146b promotes cell migration and invasion and is associated with an increased risk of recurrence (50). Recently, it has been shown that PTC cases with overexpression of miR-146b-5p and miR-21 had significantly poorer disease-free survival rates. Because miR-146b-5p was significantly overexpressed in PTC, including fvPTC, but not in other analyzed tissues, the authors suggested its possible use as both a diagnostic and a prognostic marker for PTC (39). Similar conclusions were drawn from a study analyzing miR-146b and miR221/222 cluster. Higher expression levels of those miRs were detected in cancers presenting with capsular and vascular invasion or lymph node metastasis (51). OncomiRs miR-221 and miR-222 were reported to play a role in PTC aggressiveness (52) and, in the Cancer Genome Atlas (TCGA) data, were associated with less-differentiated tumors (47). In TCGA data, a more aggressive phenotype of thyroid cancer was also correlated with overexpression of miR-21 and miR-146b, as well as the loss of miR-204 (47). Later, the expression levels of miR-21 and miR-9 were also associated with the metastatic potential of tumor cells and proved to be good predictors of nodal metastasis (53).

In another study, miR-181a-2-3p and miR-99b-3p predicted a relapse-free survival of fvPTC patients, providing a potentially important diagnostic and predictive value (46). Similar markers were proposed for minimally invasive FTCs. MiR-10b, -92a and -221/222 cluster were significantly elevated in a group of metastatic cancers, and the expression of miR-10b was proposed to be a prognostic factor for the evaluation of the metastatic potential of minimally invasive FTC with an $\mathrm{OR}=19.8$ (54). In a study by Xiong et al., the expression levels of miR-126-3p were negatively correlated with tumor size and worse clinical outcome of both FTC and PTC patients. In vitro and invivo analyses showed that overexpression of miR-126-3p led to the inhibition of cell proliferation, colony formation, vascular endothelial growth factor secretion, and a decrease of the metastatic potential (55). Thus, it seems that microRNAs could be potentially useful for the noninvasive monitoring of thyroid status and thyroid cancer recurrence.

\section{MicroRNAs in cancer therapies}

The role of microRNAs in the pathogenesis of cancer is becoming more and more striking. A novel study revealed 
that microRNAs and microRNA processing complexes are directly involved in the cellular adhesion mediated by E-cadherin and p120 catenin (56). Unlike genetic changes, microRNA alterations can be modulated, thus the significant deregulation of microRNA levels in cancer seems to be a promising therapeutic target. The biological impact of upregulated microRNAs can be abolished with specific inhibitors or anti-miRs, which are synthetic molecules that prevent binding of a miR to its targets. Lowered levels of a microRNA can be reversed by its directed upregulation, accomplished through the delivery of synthetic mature microRNA mimics, as in the synthetic RNA (siRNA) technology $(57,58)$, or the delivery of primary microRNAs (shmiR) or microRNA precursors (shRNA) expressed from plasmids $(59,60,61)$.

Studies on mouse models confirmed the potential utility of microRNA targeted therapies; however, numerous questions still have to be answered before most of these results can be further directed to clinical trials. The first milestone in the studies on the use of microRNAs as therapeutic agents was a preclinical study in which miR122 inhibitors were tested in chimpanzees as a therapy for chronic hepatitis C. i.v. delivery of the microRNA inhibitor resulted in a significant decrease of hepatitis $C$ virus viremia, and the tested molecule proved to be of low toxicity (62). Another study, which reached the first clinical phase, was conducted in patients with unresectable primary liver cancer. The patients were treated with a MRX34 molecule, mimicking miR-34, a potent regulator of 24 oncogenes overexpressed in liver cancer (63). The closing date of the study is scheduled for December 2015. The quest to identify microRNA-based strategies continues. According to ClinicalTrials.gov, a service maintained by the U.S. National Institutes of Health, 272 microRNA studies are currently registered, and patients are being recruited or the recruitment will begin soon for another 145 studies. However, the registered clinical trials are mainly focused on the diagnostic use of miRs, specifically on the elaboration of diagnostic panels based on circulating microRNAs.

\section{The potential of microRNAs in thyroid cancer treatment}

Although so far there have been no reports on the clinical use of microRNAs in the thyroid cancer treatment, numerous functional and preclinical studies indicate strong potential for this field. The vast number of studies focuses on PTC as the most common thyroid carcinoma. Functional analyses led to the identification of microRNAs with a tumor-suppressive role in this cancer. Overexpression of miR-101 (64) and miR-145 (49), both downregulated in PTC, led to decreased cell proliferation, migration, and invasion. Similar effects were observed for miR-199a-3p, which induced non-apoptotic cell death in a PTC-derived cell line (65). Similarly, miR-291-5p was downregulated in PTC tumors, and the forced expression of the miR suppressed PTC cell proliferation and migration, as well as promoted apoptosis. This effect of miR-291-5p on PTC occurrence and behavior was possibly mediated by estrogen receptor $\alpha(\mathrm{ER} \alpha)$, its direct target (66). Among the top upregulated microRNAs in PTC, miR146b-5p plays a role in the cell proliferation and invasion and was shown to be transiently upregulated during epithelial-mesenchymal transition (EMT) (67).

Other studies indicate the potential of microRNAs not only in the regulation of tumor growth but also in adjuvant therapies in thyroid cancer. Many patients with advanced thyroid cancer do not benefit from the radioiodine therapy due to the reduced expression and function of the $\mathrm{Na}^{+} / \mathrm{I}^{-}$symporter (NIS). It was shown that lowered levels of NIS in thyroid tumors are at least in part caused by the overexpression of miR-339 and miR-146b, and inhibition of these microRNAs results in the increased uptake of radioactive iodine by the thyroid cancer cells $(68,69,70)$.

Data obtained in the in vitro experiments provided the basis for a number of preclinical studies related to the modulation of microRNAs in PTC, currently performed mainly on mouse models. S.c. transplantation of the human PTC cell line stably expressing miR-204-5p to $\mathrm{BALB} / \mathrm{c}$ nude mice revealed that the overexpression of $\mathrm{miR}$ resulted in a lower tumor size compared with tumors induced by the injection of control cells (71). Because miR204-5p is downregulated in cancer and was proposed a tumor suppressor, this result supports its crucial role in the tumor transformation and growth, possibly mediated via targeting the insulin-like growth factor-binding protein 5 (IGFBP-5). Another interesting study analyzed miR-155, an oncomiR frequently upregulated in PTC. Its overexpression in a mouse model induced the growth of larger and more intensively proliferating tumors (72). A number of studies evaluated the possible use of microRNA inhibitors in modulating cellular miRNA levels. The inhibition of miR-182 in TPC- 1 cells injected to BALC/c nude mice resulted in the slower tumor growth compared with mice injected with control cells. These results indicate a potential role of miR-182 as an oncogene in PTC and a putative therapeutic target in this cancer (73). In yet another study, Frezzetti et al. proved that the 
injection of constitutive Ras-transformed FRTL-5 cells with inhibitors of miR-21 resulted in the decrease of tumor growth (74).

As opposed to PTC, functional studies on the role of miRs in FTC and PDTCs are scarce. The study by Xiong et al. showed that similar miRs may play a role in the pathogenesis of PTC and FTC, as miR-126-3p, implicated in the pathogenesis of PTC, was significantly lower in FTC compared with FA specimens (55). Other functional studies suggested the impact of miR-183 and miR-146b, upregulated in FTC, on cancer development. Their overexpression in cell lines induced migration, and overexpression of miR-183 significantly repressed apoptosis (75). In another study, let-7a was found to be downregulated in FTC compared with FA, and functional assays revealed that enforced let-7a expression in the FTCderived cell line induced epithelial-like phenotype, increased cell adhesion, and decreased cell migration. As a proof of these effects, silencing let-7a in the normal rat thyroid cell line PCCl3 had the opposite outcome (76). Similar results were observed for miR-142-3p that also seems to play a tumor-suppressive role in the thyroid gland. Its downregulation in tumor was associated with the aberrant action of Trithorax group proteins, major regulators of the homeobox gene expression (77). Another study revealed an important role of miR-122 significantly upregulated in FTC compared with FA. This upregulation was associated with the presence of the PAX8/PPAR $\gamma$ fusion protein, which, paradoxically, led to a minimally invasive behavior of tumor. Functional studies revealed that overexpression of miR-122 in a mouse xenograft model resulted in a significant reduction of tumor progression (78).

In ATC, the role of highly downregulated miR-200 and miR-30 has been studied for some time already. Expression of these microRNAs in mesenchymal ATC-derived cells reduced their invasive potential and induced EMT by regulating the expression of SMAD2 and TGFBR1, upregulated in most ATCs (79). Further studies supported the role of miR-200 deregulation in EMT of thyroid cancer cells (80). The authors showed that re-expression of miR200 restores the epithelial phenotype, abrogating the epidermal growth factor treatment, and they proposed the upregulation of the miR-200 family as a novel therapeutic strategy in highly invasive thyroid cancers. Another study on the possible use of miRs in therapies of ATC focused on mir-30a, which turned out to be a direct negative regulator of lysis oxidase (LOX). Restored expression of miR-30a in a mouse model resulted in smaller metastases but did not affect the tumor growth
(81). The role of the miR-30 family in the pathogenesis of ATC was additionally supported in a study by Hebrant et al. (82), which also identified miR-29a as the second regulator of the $L O X$ gene. Novel studies identified other microRNAs, miR-21 (83) and miR-4295 (84), as potential oncomiRs in ATC. In ATC-derived cell lines, the inhibition of both miRs induced cell differentiation and apoptosis. In the case of miR-4395, this effect was possibly mediated through a direct interaction with its target gene, CDKN1A (84). As already mentioned in the section on FTC studies, miR-122 and miR-375 are upregulated by the PAX8/PPAR $\gamma$ fusion protein, and these phenomena are associated with decreased angiogenesis and AKT pathway inactivation. Thus, it was proposed that PAX8/PPAR $\gamma$-induced expression of miR-122 and miR-375 can serve as a novel therapeutic strategy for ATC (85).

All above studies underline the high potential of miRs as novel therapeutic and diagnostic tools in thyroid carcinomas.

\section{Declaration of interest}

The authors declare that there is no conflict of interest that could be perceived as prejudicing the impartiality of this review.

\section{Funding}

This work was supported by Ministry of Science and Higher Education grant 0525/IP1/2015/73, Polish National Science Centre grant DEC-2012/ 07/D/NZ3/04149, DEC-2012/07/N/NZ3/02033, and DEC-2013/11/B/NZ3/00193. The authors were supported by the Foundation for Polish Science, Programme TEAM, co-financed by the European Union European Regional Development Fund. The Department of Genomic Medicine of the Medical University of Warsaw participates in Bastion, a programme financed by the European Union (FP7-REGPOT-2012-CT2012-316254-BASTION).

\section{References}

1 Sood P, Krek A, Zavolan M, Macino G \& Rajewsky N. Cell-type-specific signatures of microRNAs on target mRNA expression. PNAS 2006103 2746-2751. (doi:10.1073/pnas.0511045103)

2 Lu J, Getz G, Miska EA, Alvarez-Saavedra E, Lamb J, Peck D, Sweet-Cordero A, Ebert BL, Mak RH, Ferrando AA et al. MicroRNA expression profiles classify human cancers. Nature 2005435 834-838. (doi:10.1038/nature03702)

3 Meng W, McElroy JP, Volinia S, Palatini J, Warner S, Ayers LW, Palanichamy K, Chakravarti A \& Lautenschlaeger T. Comparison of microRNA deep sequencing of matched formalin-fixed paraffinembedded and fresh frozen cancer tissues. PLOS ONE 20138 e64393. (doi:10.1371/journal.pone.0064393)

4 Mitchell PS, Parkin RK, Kroh EM, Fritz BR, Wyman SK, PogosovaAgadjanyan EL, Peterson A, Noteboom J, O'Briant KC, Allen A et al. Circulating microRNAs as stable blood-based markers for cancer detection. PNAS 2008105 10513-10518. (doi:10.1073/pnas. 0804549105) 
5 Bartel DP. MicroRNAs: target recognition and regulatory functions. Cell 2009136 215-233. (doi:10.1016/j.cell.2009.01.002)

6 Helwak A, Kudla G, Dudnakova T \& Tollervey D. Mapping the human miRNA interactome by CLASH reveals frequent noncanonical binding. Cell 2013153 654-665. (doi:10.1016/j.cell.2013.03.043)

7 Krol J, Loedige I \& Filipowicz W. The widespread regulation of microRNA biogenesis, function and decay. Nature Reviews. Genetics 201011 597-610. (doi:10.1038/nrg2843)

8 Subramanian S \& Steer CJ. MicroRNAs as gatekeepers of apoptosis. Journal of Cellular Physiology 2010223 289-298. (doi:10.1002/jcp.22066)

9 Esquela-Kerscher A \& Slack FJ. Oncomirs - microRNAs with a role in cancer. Nature Reviews. Cancer 20066 259-269. (doi:10.1038/nrc1840)

10 Wang J, Lu M, Qiu C \& Cui Q. TransmiR: a transcription factormicroRNA regulation database. Nucleic Acids Research 201038 D119-D122. (doi:10.1093/nar/gkp803)

11 Calin GA, Sevignani C, Dan Dumitru C, Hyslop T, Noch E, Yendamuri S, Shimizu M, Rattan S, Bullrich F, Negrini M et al. Human microRNA genes are frequently located at fragile sites and genomic regions involved in cancers. PNAS 2004101 2999-3004. (doi:10.1073/ pnas.0307323101)

12 Friedman RC, Farh KKH, Burge CB \& Bartel DP. Most mammalian mRNAs are conserved targets of microRNAs. Genome Research 200919 92-105. (doi:10.1101/gr.082701.108)

13 Saini HK, Griffiths-Jones S \& Enright AJ. Genomic analysis of human microRNA transcripts. PNAS 2007104 17719-17724. (doi:10.1073/ pnas.0703890104)

14 Morin RD, O'Connor MD, Griffith M, Kuchenbauer F, Delaney A, Prabhu AL, Zhao Y, McDonald $\mathrm{H}$, Zeng T, Hirst $\mathrm{M}$ et al. Application of massively parallel sequencing to microRNA profiling and discovery in human embryonic stem cells. Genome Research 200818 610-621. (doi:10.1101/gr.7179508)

15 Cloonan N, Wani S, Xu Q, Gu J, Lea K, Heater S, Barbacioru C, Steptoe AL, Martin HC, Nourbakhsh E et al. MicroRNAs and their isomiRs function cooperatively to target common biological pathways. Genome Biology 201112 R126. (doi:10.1186/gb-2011-12-12-r126)

16 Wojcicka A, Swierniak M, Kornasiewicz O, Gierlikowski W, Maciag M, Kolanowska M, Kotlarek M, Gornicka B, Koperski L, Niewinski G et al. Next generation sequencing reveals microRNA isoforms in liver cirrhosis and hepatocellular carcinoma. International Journal of Biochemistry \& Cell Biology 201453 208-217. (doi:10.1016/j.biocel.2014. 05.020)

17 Tan GC, Chan E, Molnar A, Sarkar R, Alexieva D, Isa IM, Robinson S, Zhang SC, Ellis P, Langford CF et al. 5 ' isomiR variation is of functional and evolutionary importance. Nucleic Acids Research 201442 9424-9435. (doi:10.1093/nar/gku656)

18 Griffiths-Jones S, Saini HK, van Dongen S \& Enright AJ. miRBase: tools for microRNA genomics. Nucleic Acids Research 200836 D154-D158. (doi:10.1093/nar/gkm952)

19 Swierniak M, Wojcicka A, Czetwertynska M, Stachlewska E, Maciag M, Wiechno W, Gornicka B, Bogdanska M, Koperski L, de la Chapelle A et al. In-depth characterization of the microRNA transcriptome in normal thyroid and papillary thyroid carcinoma. Journal of Clinical Endocrinology and Metabolism 201398 E1401-E1409. (doi:10.1210/jc. 2013-1214)

20 Weber F, Teresi RE, Broelsch CE, Frilling A \& Eng C. A limited set of human MicroRNA is deregulated in follicular thyroid carcinoma. Journal of Clinical Endocrinology and Metabolism 200691 3584-3591. (doi:10.1210/jc.2006-0693)

21 He H, Jazdzewski K, Li W, Liyanarachchi S, Nagy R, Volinia S, Calin GA, Liu CG, Franssila K, Suster S et al. The role of microRNA genes in papillary thyroid carcinoma. PNAS 2005102 19075-19080. (doi:10.1073/pnas.0509603102)

22 Pallante P, Visone R, Ferracin M, Ferraro A, Berlingieri MT, Troncone G, Chiappetta G, Liu CG, Santoro M, Negrini M et al. MicroRNA deregulation in human thyroid papillary carcinomas. Endocrine-Related Cancer 200613 497-508. (doi:10.1677/erc.1.01209)
23 Roncati L, Pignatti E, Vighi E, Magnani E, Kara E, Rochira V, Carani C, Simoni M \& Maiorana A. Pre-miR146a expression in follicular carcinomas of the thyroid. Pathologica 2014106 58-60.

24 Visone R, Pallante P, Vecchione A, Cirombella R, Ferracin M, Ferraro A, Volinia S, Coluzzi S, Leone V, Borbone E et al. Specific microRNAs are downregulated in human thyroid anaplastic carcinomas. Oncogene 200726 7590-7595. (doi:10.1038/sj.onc.1210564)

25 Mancikova V, Castelblanco E, Pineiro-Yanez E, Perales-Paton J, de Cubas AA, Inglada-Perez L, Matias-Guiu X, Capel I, Bella M, Lerma E et al. MicroRNA deep-sequencing reveals master regulators of follicular and papillary thyroid tumors. Modern Pathology 201528 748-757. (doi:10.1038/modpathol.2015.44)

26 Jazdzewski K, Murray EL, Franssila K, Jarzab B, Schoenberg DR, de la Chapelle A \& Common SNP. in pre-miR-146a decreases mature miR expression and predisposes to papillary thyroid carcinoma. PNAS 2008 105 7269-7274. (doi:10.1073/pnas.0802682105)

27 Jazdzewski K, Liyanarachchi S, Swierniak M, Pachucki J, Ringel MD, Jarzab B \& de la Chapelle A. Polymorphic mature microRNAs from passenger strand of pre-miR-146a contribute to thyroid cancer. PNAS 2009106 1502-1505. (doi:10.1073/pnas.0812591106)

28 Jones AM, Howarth KM, Martin L, Gorman M, Mihai R, Moss L, Auton A, Lemon C, Mehanna H, Mohan $\mathrm{H}$ et al. Thyroid cancer susceptibility polymorphisms: confirmation of loci on chromosomes 9q22 and 14q13, validation of a recessive 8q24 locus and failure to replicate a locus on 5q24. Journal of Medical Genetics 201249 158-163. (doi:10.1136/jmedgenet-2011-100586)

29 Wei WJ, Wang YL, Li DS, Wang Y, Wang XF, Zhu YX, Yang YJ, Wang ZY, Ma YY, Wu Y et al. Association between the rs2910164 polymorphism in pre-Mir-146a sequence and thyroid carcinogenesis. PLoS ONE 20138 e56638. (doi:10.1371/journal.pone.0056638)

30 Marino M, Cirello V, Gnarini V, Colombo C, Pignatti E, Casarini L, Diazzi C, Rochira V, Cioni K, Madeo B et al. Are pre-miR-146a and PTTG1 associated with papillary thyroid cancer? Endocrine Connections 20132 178-185. (doi:10.1530/EC-13-0066)

31 Xu T, Zhu Y, Wei QK, Yuan Y, Zhou F, Ge YY, Yang JR, Su H \& Zhuang SM. A functional polymorphism in the miR-146a gene is associated with the risk for hepatocellular carcinoma. Carcinogenesis 200829 2126-2131. (doi:10.1093/carcin/bgn195)

$32 \mathrm{Xu}$ B, Feng NH, Li PC, Tao J, Wu D, Zhang ZD, Tong N, Wang JF, Song NH, Zhang W et al. A functional polymorphism in Pre-miR-146a gene is associated with prostate cancer risk and mature miR-146a expression in vivo. Prostate 201070 467-472. (doi:10.1002/pros.21149)

33 Wang M, Chu H, Li P, Yuan L, Fu G, Ma L, Shi D, Zhong D, Tong N, Qin C et al. Genetic variants in miRNAs predict bladder cancer risk and recurrence. Cancer Research 201272 6173-6182. (doi:10.1158/ 0008-5472.CAN-12-0688)

34 Ma L, Zhu L, Gu D, Chu H, Tong N, Chen J, Zhang Z \& Wang M. A genetic variant in miR-146a modifies colorectal cancer susceptibility in a Chinese population. Archives of Toxicology 201387 825-833. (doi:10.1007/s00204-012-1004-2)

35 Shen J, Ambrosone CB, DiCioccio RA, Odunsi K, Lele SB \& Zhao H. A functional polymorphism in the miR-146a gene and age of familial breast/ovarian cancer diagnosis. Carcinogenesis 200829 1963-1966. (doi:10.1093/carcin/bgn172)

36 Nikiforova MN, Tseng GC, Steward D, Diorio D \& Nikiforov YE. MicroRNA expression profiling of thyroid tumors: biological significance and diagnostic utility. Journal of Clinical Endocrinology and Metabolism 200893 1600-1608. (doi:10.1210/jc.2007-2696)

37 Agretti P, Ferrarini E, Rago T, Candelieri A, De Marco G, Dimida A, Niccolai F, Molinaro A, Di Coscio G, Pinchera A et al. MicroRNA expression profile helps to distinguish benign nodules from papillary thyroid carcinomas starting from cells of fine-needle aspiration. European Journal of Endocrinology 2012167 393-400. (doi:10.1530/ EJE-12-0400)

38 Kitano M, Rahbari R, Patterson EE, Steinberg SM, Prasad NB, Wang Y, Zeiger MA \& Kebebew E. Evaluation of candidate diagnostic microRNAs 
in thyroid fine-needle aspiration biopsy samples. Thyroid $2012 \mathbf{2 2}$ 285-291. (doi:10.1089/thy.2011.0313)

39 Guo Z, Hardin H, Montemayor-Garcia C, Asioli S, Righi A, Maletta F, Sapino A \& Lloyd RV. In situ hybridization analysis of miR-146b-5p and miR-21 in thyroid nodules: diagnostic implications. Endocrine Pathology 201526 157-163. (doi:10.1007/s12022-015-9363-x)

40 Paskas S, Jankovic J, Zivaljevic V, Tatic S, Bozic V, Nikolic A, Radojkovic D, Savin S \& Cvejic D. Malignant risk stratification of thyroid FNA specimens with indeterminate cytology based on molecular testing. Cancer Cytopathology 2015123 471-479. (doi:10.1002/cncy.21554)

41 Stokowy T, Wojtas B, Krajewska J, Stobiecka E, Dralle H, Musholt T, Hauptmann S, Lange D, Hegedus L, Jarzab B et al. A two miRNA classifier differentiates follicular thyroid carcinomas from follicular thyroid adenomas. Molecular and Cellular Endocrinology 2015399 43-49. (doi:10.1016/j.mce.2014.09.017)

42 Yu S, Liu Y, Wang J, Guo Z, Zhang Q, Yu F, Zhang Y, Huang K, Li Y, Song E et al. Circulating microRNA profiles as potential biomarkers for diagnosis of papillary thyroid carcinoma. Journal of Clinical Endocrinology and Metabolism 201297 2084-2092. (doi:10.1210/jc.2011-3059)

43 Ferracin M, Lupini L, Salamon I, Saccenti E, Zanzi MV, Rocchi A, Da Ros L, Zagatti B, Musa G, Bassi C et al. Absolute quantification of cell-free microRNAs in cancer patients. Oncotarget 20156 14545-14555. (doi:10.18632/oncotarget.3859)

44 Lee YS, Lim YS, Lee JC, Wang SG, Park HY, Kim SY \& Lee BJ. Differential expression levels of plasma-derived miR-146b and miR-155 in papillary thyroid cancer. Oral Oncology 201551 77-83. (doi:10.1016/j.oraloncology.2014.10.006)

45 Li M, Song QB, Li H, Lou Y \& Wang LL. Circulating miR-25-3p and miR451a may be potential biomarkers for the diagnosis of papillary thyroid carcinoma. PLoS ONE 201510 e0132403. (doi:10.1371/journal.pone. 0132403)

46 Dettmer M, Perren A, Moch H, Komminoth P, Nikiforov YE \& Nikiforova MN. Comprehensive MicroRNA expression profiling identifies novel markers in follicular variant of papillary thyroid carcinoma. Thyroid 201323 1383-1389. (doi:10.1089/thy.2012.0632)

47 Cancer Genome Atlas Research N . Integrated genomic characterization of papillary thyroid carcinoma. Cell 2014159 676-690. (doi:10.1016/j. cell.2014.09.050)

48 Kirschner MB, Edelman JJ, Kao SC, Vallely MP, van Zandwijk N \& Reid G. The impact of hemolysis on cell-free microRNA biomarkers. Frontiers in Genetics 20134 94. (doi:10.3389/fgene.2013.00094)

49 Boufraqech M, Zhang L, Jain M, Patel D, Ellis R, Xiong Y, He M, Nilubol N, Merino MJ \& Kebebew E. miR-145 suppresses thyroid cancer growth and metastasis and targets AKT3. Endocrine-Related Cancer 2014 21 517-531. (doi:10.1530/ERC-14-0077)

50 Chou CK, Yang KD, Chou FF, Huang CC, Lan YW, Lee YF, Kang HY \& Liu RT. Prognostic implications of miR-146b expression and its functional role in papillary thyroid carcinoma. Journal of Clinical Endocrinology and Metabolism 201398 E196-E205. (doi:10.1210/jc. 2012-2666)

51 Acibucu F, Dokmetas HS, Tutar Y, Elagoz S \& Kilicli F. Correlations between the expression levels of micro-RNA146b, 221, 222 and p27Kip1 protein mRNA and the clinicopathologic parameters in papillary thyroid cancers. Experimental and Clinical Endocrinology \& Diabetes 2014122 137-143. (doi:10.1055/s-0034-1367025)

52 Mardente S, Mari E, Consorti F, Di Gioia C, Negri R, Etna M, Zicari A \& Antonaci A. HMGB1 induces the overexpression of miR-222 and miR221 and increases growth and motility in papillary thyroid cancer cells. Oncology Reports 201228 2285-2289. (doi:10.3892/or.2012.2058)

53 Sondermann A, Andreghetto FM, Moulatlet AC, da Silva Victor E, de Castro MG, Nunes FD, Brandao LG \& Severino P. MiR-9 and miR-21 as prognostic biomarkers for recurrence in papillary thyroid cancer. Clinical \& amp;Translational Oncology 201532 521-530. (doi:10.1007/ s10585-015-9724-3)
54 Jikuzono T, Kawamoto M, Yoshitake H, Kikuchi K, Akasu H, Ishikawa H, Hirokawa M, Miyauchi A, Tsuchiya S, Shimizu K et al. The miR-221/222 cluster, miR-10b and miR-92a are highly upregulated in metastatic minimally invasive follicular thyroid carcinoma. International Journal of Oncology 201342 1858-1868. (doi:10.3892/ijo.2013.1879)

55 Xiong Y, Kotian S, Zeiger MA, Zhang L \& Kebebew E. miR-126-3p inhibits thyroid cancer cell growth and metastasis, and is associated with aggressive thyroid cancer. PLoS ONE 201510 e0130496. (doi:10. 1371/journal.pone.0130496)

56 Kourtidis A, Ngok SP, Pulimeno P, Feathers RW, Carpio LR, Baker TR, Carr JM, Yan IK, Borges S, Perez EA et al. Distinct E-cadherin-based complexes regulate cell behaviour through miRNA processing or Src and p120 catenin activity. Nature Cell Biology 201517 1145-1157. (doi:10.1038/ncb3227)

57 Bartlett DW \& Davis ME. Insights into the kinetics of siRNA-mediated gene silencing from live-cell and live-animal bioluminescent imaging. Nucleic Acids Research 200634 322-333. (doi:10.1093/nar/gkj439)

58 Bartlett DW \& Davis ME. Impact of tumor-specific targeting and dosing schedule on tumor growth inhibition after intravenous administration of siRNA-containing nanoparticles. Biotechnology and Bioengineering 200899 975-985. (doi:10.1002/bit.21668)

59 Chang K, Elledge SJ \& Hannon GJ. Lessons from nature: microRNAbased shRNA libraries. Nature Methods 20063 707-714. (doi:10.1038/ nmeth923)

60 Boudreau RL, Martins I \& Davidson BL. Artificial microRNAs as siRNA shuttles: improved safety as compared to shRNAs in vitro and in vivo. Molecular Therapy 200917 169-175. (doi:10.1038/mt.2008.231)

61 Ge Q, Ilves H, Dallas A, Kumar P, Shorenstein J, Kazakov SA \& Johnston BH. Minimal-length short hairpin RNAs: the relationship of structure and RNAi activity. RNA 201016 106-117. (doi:10.1261/rna. 1894510)

62 Lanford RE, Hildebrandt-Eriksen ES, Petri A, Persson R, Lindow M, Munk ME, Kauppinen S \& Orum H. Therapeutic silencing of microRNA122 in primates with chronic hepatitis C virus infection. Science 2010 327 198-201. (doi:10.1126/science.1178178)

63 Bouchie A. First microRNA mimic enters clinic. Nature Biotechnology 201331 577. (doi:10.1038/nbt0713-577)

64 Wang CH, Lu SJ, Jiang JX, Jia XQ, Dong XY \& Bu P. Hsa-microRNA-101 suppresses migration and invasion by targeting Rac1 in thyroid cancer cells. Oncology Letters 20148 1815-1821. (doi:10.3892/ol.2014.2361)

65 Minna E, Romeo P, De Cecco L, Dugo M, Cassinelli G, Pilotti S, Degl'Innocenti D, Lanzi C, Casalini P, Pierotti MA et al. miR-199a-3p displays tumor suppressor functions in papillary thyroid carcinoma. Oncotarget 20145 2513-2528. (doi:10.18632/oncotarget.1830)

66 Huang C, Cai Z, Huang M, Mao C, Zhang Q, Lin Y, Zhang X, Tang B, Chen $Y$, Wang $X$ et al. miR-219-5p modulates cell growth of papillary thyroid carcinoma by targeting estrogen receptor alpha. Journal of Clinical Endocrinology and Metabolism 2015100 E204-E213. (doi:10.1210/jc.2014-2883)

67 Hardin H, Guo Z, Shan W, Montemayor-Garcia C, Asioli S, Yu XM, Harrison AD, Chen $\mathrm{H} \&$ Lloyd RV. The roles of the epithelialmesenchymal transition marker PRRX1 and miR-146b-5p in papillary thyroid carcinoma progression. American Journal of Pathology 2014184 2342-2354. (doi:10.1016/j.ajpath.2014.04.011)

68 Lakshmanan A, Wojcicka A, Kotlarek M, Zhang X, Jazdzewski K \& Jhiang SM. microRNA-339-5p modulates Na +/I- symporter-mediated radioiodide uptake. Endocrine-Related Cancer 201522 11-21. (doi:10.1530/ERC-14-0439)

69 Li L, Lv B, Chen B, Guan M, Sun Y, Li H, Zhang B, Ding C, He S \& Zeng Q. Inhibition of miR-146b expression increases radioiodinesensitivity in poorly differential thyroid carcinoma via positively regulating NIS expression. Biochemical and Biophysical Research Communications 2015462 314-321. (doi:10.1016/j.bbrc.2015.04.134)

70 Riesco-Eizaguirre G, Wert-Lamas L, Perales-Paton J, Sastre-Perona A, Fernandez LP \& Santisteban P. The miR-146b-3p/PAX8/NIS regulatory circuit modulates the differentiation phenotype and function of 
thyroid cells during carcinogenesis. Cancer Research 201575 4119-4130. (doi:1158/0008-5472.CAN-14-3547)

71 Liu L, Wang J, Li X, Ma J, Shi C, Zhu H, Xi Q, Zhang J, Zhao X \& Gu M. MiR-204-5p suppresses cell proliferation by inhibiting IGFBP5 in papillary thyroid carcinoma. Biochemical and Biophysical Research Communications 2015457 621-626. (doi:10.1016/j.bbrc.2015.01.037)

72 Zhang X, Li M, Zuo K, Li D, Ye M, Ding L, Cai H, Fu D, Fan Y \& Lv Z. Upregulated miR-155 in papillary thyroid carcinoma promotes tumor growth by targeting APC and activating Wnt/beta-catenin signaling. Journal of Clinical Endocrinology and Metabolism 201398 E1305-E1313. (doi:10.1210/jc.2012-3602)

73 Zhu H, Fang J, Zhang J, Zhao Z, Liu L, Wang J, Xi Q \& Gu M. miR-182 targets CHL1 and controls tumor growth and invasion in papillary thyroid carcinoma. Biochemical and Biophysical Research Communications 2014450 857-862. (doi:10.1016/j.bbrc.2014.06.073)

74 Frezzetti D, De Menna M, Zoppoli P, Guerra C, Ferraro A, Bello AM, De Luca P, Calabrese C, Fusco A, Ceccarelli M et al. Upregulation of miR-21 by Ras in vivo and its role in tumor growth. Oncogene 201130 275-286. (doi:10.1038/onc.2010.416)

75 Wojtas B, Ferraz C, Stokowy T, Hauptmann S, Lange D, Dralle H, Musholt T, Jarzab B, Paschke R \& Eszlinger M. Differential miRNA expression defines migration and reduced apoptosis in follicular thyroid carcinomas. Molecular and Cellular Endocrinology 2014388 1-9. (doi:10.1016/j.mce.2014.02.011)

76 Colamaio M, Cali G, Sarnataro D, Borbone E, Pallante P, DecaussinPetrucci M, Nitsch L, Croce CM, Battista S \& Fusco A. Let-7a downregulation plays a role in thyroid neoplasias of follicular histotype affecting cell adhesion and migration through its ability to target the FXYD5 (Dysadherin) gene. Journal of Clinical Endocrinology and Metabolism 201297 E2168-E2178. (doi:10.1210/jc.2012-1929)

77 Colamaio M, Puca F, Ragozzino E, Gemei M, Decaussin-Petrucci M, Aiello C, Bastos AU, Federico A, Chiappetta G, Del Vecchio L et al. miR142-3p down-regulation contributes to thyroid follicular tumorigenesis by targeting ASH1L and MLL1. Journal of Clinical Endocrinology and Metabolism 2015100 E59-E69. (doi:10.1210/jc.2014-2280)
78 Reddi HV, Madde P, Milosevic D, Hackbarth JS, Algeciras-Schimnich A, McIver B, Grebe SK \& Eberhardt NL. The putative PAX8/PPARgamma fusion oncoprotein exhibits partial tumor suppressor activity through up-regulation of micro-RNA-122 and dominant-negative PPAR gamma activity. Genes \& cancer 20112 46-55. (doi:10.1177/ 1947601911405045)

79 Braun J, Hoang-Vu C, Dralle H \& Huttelmaier S. Downregulation of microRNAs directs the EMT and invasive potential of anaplastic thyroid carcinomas. Oncogene 201029 4237-4244. (doi:10.1038/onc.2010.169)

80 Zhang Z, Liu ZB, Ren WM, Ye XG \& Zhang YY. The miR-200 family regulates the epithelial-mesenchymal transition induced by EGF/EGFR in anaplastic thyroid cancer cells. International Journal of Molecular Medicine 201230 856-862. (doi:10.3892/ijmm.2012.1059)

81 Boufraqech M, Nilubol N, Zhang L, Gara SK, Sadowski SM, Mehta A, He M, Davis S, Dreiling J, Copland JA et al. miR30a inhibits LOX expression and anaplastic thyroid cancer progression. Cancer Research 201575 367-377. (doi:10.1158/0008-5472.CAN-14-2304)

82 Hebrant A, Floor S, Saiselet M, Antoniou A, Desbuleux A, Snyers B, La C, de Saint Aubain N, Leteurtre E, Andry G \& Maenhaut C. miRNA expression in anaplastic thyroid carcinomas. PLOS ONE 20149 e103871. (doi:10.1371/journal.pone.0103871)

83 Haghpanah V, Fallah P, Tavakoli R, Naderi M, Samimi H, Soleimani M $\&$ Larijani B. Antisense-miR-21 enhances differentiation/apoptosis and reduces cancer stemness state on anaplastic thyroid cancer. Tumour Biology 2015. In press. (doi:10.1007/s13277-015-3923-z)

84 Shao M, Geng Y, Lu P, Xi Y, Wei S, Wang L, Fan Q \& Ma W. miR-4295 promotes cell proliferation and invasion in anaplastic thyroid carcinoma via CDKN1A. Biochemical and Biophysical Research Communications 2015464 1309-1313. (doi:10.1016/ j.bbrc.2015.07.128)

85 Reddi HV, Driscoll CB, Madde P, Milosevic D, Hurley RM, McDonough SJ, Hallanger-Johnson J, McIver B \& Eberhardt NL. Redifferentiation and induction of tumor suppressors miR-122 and miR-375 by the PAX8/PPARgamma fusion protein inhibits anaplastic thyroid cancer: a novel therapeutic strategy. Cancer Gene Therapy 2013 20 267-275. (doi:10.1038/cgt.2013.16)

Received 30 June 2015

Revised version received 15 October 2015

Accepted 26 October 2015 